\title{
Smac deficiency affects endoplasmic reticulum stress- induced apoptosis in human colon cancer cells
}

\author{
Qin He*, Jingxue Shi*, Samantha Jones, Jie An, Yuxin Liu, Ying Huang and \\ M. Saeed Sheikh \\ Department of Pharmacology, State University of New York, Upstate Medical University, \\ Syracuse, New York
}

*These authors contributed equally to this work.

\begin{abstract}
Thapsigargin (TG) is a sesquiterpen lactone that inhibits the endoplasmic reticulum (ER) calcium ATPases to disrupt calcium homeostasis and consequently induces ER stress. We have previously reported that TG induces apoptosis by engaging the death receptor 5 (DR5) and the intrinsic pathways. Second mitochondrial-derived activator (Smac) is an important modulator of apoptosis that induces activation of caspases by antagonizing inhibitors of apoptosis (IAPs). In this study, we have utilized Smac-proficient and deficient human colon cancer cells to investigate the effects of Smac deficiency during ER-stressinduced apoptosis. Our results indicate that Smac deficiency considerably affects ER stress-induced apoptosis in human colon cancer cells. For example, ER stress inducing agent TG upregulates DR5, and activates caspases 3,9 and 8 in Smacproficient cells. In Smac-deficient cells, although TG-induced DR5 upregulation is not affected, activation of caspases 3,9 and 8 is affected. Smac deficiency also affects TG-induced cytochrome c release from mitochondria into cytosol suggesting the existence of a potential cross-talk between Smac and cytochrome c. Thus, our results indicate that ER stress-induced apoptosis also engages Smac for transduction of apoptotic signals in human colon cancer cells and that a potential feedback signaling between Smac and cytochrome c appears to modulate the intrinsic pathway of apoptosis.
\end{abstract}

Received 01/26/09; accepted 02/05/09

Correspondence: M. Saeed Sheikh, M.D., Ph.D., Department of Pharmacology, SUNY Upstate Medical University, 750 E. Adams St. Syracuse, NY 13210, USA. Tel. 315-464-8015, Fax. 315-464-8014. email: sheikhm@upstate.edu
Keywords: Smac; Endoplasmic reticulum stress; Death receptor 5; Caspases; Apoptosis

Introduction

A large body of evidence indicates that alterations in cellular $\mathrm{Ca}^{2+}$ levels can induce apoptosis (1-5), but the in-depth molecular mechanisms have not been fully elucidated. Thapsigargin (TG), a sesquiterpene lactone inhibits endoplasmic reticulum (ER) $\mathrm{Ca}^{2+}$ ATPases and thereby affects $\mathrm{Ca}^{2+}$ homoeostasis (6). For example, TG-mediated inhibition of ER $\mathrm{Ca}^{2+}$ ATPases interferes with the reuptake of cytosolic $\mathrm{Ca}^{2+}$ into the ER, resulting in increase and decrease of $\mathrm{Ca}^{2+}$ levels in cytosol and the ER respectively (6). It is believed that TG-mediated depletion of $\mathrm{ER} \mathrm{Ca}^{2+}$ stores induces ER stress that eventually triggers apoptosis. Several lines of evidence suggest that members of the $\mathrm{Bcl}-2$ family including $\mathrm{Bcl}-2$, BclxL and Bax are important modulators of TG-induced apoptosis $(3,4)$. For example, Bcl-2 that interacts with the ER and mitochondrial membranes (7) is thought to control the endoplasmic reticulum (ER) and mitochondrial $\mathrm{Ca}^{2+}$ homeostasis as well as the release of cytochrome $\mathrm{c}$ from mitochondria into cytosol (4, 8-10). Bax, the pro-apoptotic member is also believed be important in modulating apoptosis that occurs as a result of alterations in cellular $\mathrm{Ca}^{2+}$ homeostasis (3, 11). Bax, normally a cytosolic protein, translocates to mitochondria in response to apoptotic signals that affect $\mathrm{Ca}^{2+}$ homeostasis (11-15) and its translocation to mitochondria is thought to induce cytochrome c release of into cytosol and activation of the intrinsic pathway of apoptosis (16).

Smac, (second mitochondria-derived activator of caspases) also known as DIABLO (direct IAP binding protein with low pI) (hereafter referred to as Smac), is another mitochondrial protein that is 
released into cytosol in response to various apoptotic signals $(17,18)$. Although the exact mechanism by which Smac mediates its pro-apoptotic effect remains to be fully elucidated, several lines of evidence indicate that Smac mediates its pro- $^{-}$ apoptotic function by inhibiting proteins in the IAP (inhibitors of apoptosis) family (19-22). In this context, Smac interactions with XIAP, a prominent member of the IAP family have been extensively studied (19-22). XIAP, an anti-apoptotic molecule, is believed to mediate its function by inhibiting caspases 3, 7 and 9 (23), and Smac interferes with XIAP's ability to inhibit these caspases. Although the exact mechanism by which Smac inhibits XIAP is being elucidated, multiple lines of evidence from structural studies indicate that Smac in dimeric conformation, utilizes its tetrapeptide region harboring alanine, valine, proline and isoleucine (AVPI) to interact with BIR2 or BIR3 domains of XIAP (19-25). In view of its antagonistic effects on XIAP, Smac serves as an attractive template to design small molecules with therapeutic potential. Indeed, several Smac mimetic small molecule inhibitors of XIAP are currently being developed as potential anticancer agents (26).

Smac is an important pro-apoptotic molecule however, its role in ER stress-induced apoptosis has not been thoroughly investigated. In this study, we have used Smac-proficient $\left(\mathrm{Smac}^{+/+}\right)$and -deficient $\left(\mathrm{Smac}^{-/}\right)$HCT116 human colon cancer cell lines (27) to investigate the role of Smac in ER stress-induced apoptosis.

\section{Materials and Methods Materials}

TG was purchased from Sigma Chemicals (St. Louis, MO, USA). McCoy's 5A cell culture media, Penicillin/Streptomycin and L-Glutamine were from Mediatech, Inc (Manassas, VA, USA) and the fetal bovine serum was bought from Gemini Bioproducts (Calabasas, CA, USA).

\section{Cell lines and cell culture}

Smac-proficient $\left(\mathrm{Smac}^{+/+}\right)$and -deficient $\left(\mathrm{Smac}^{-/}\right)$ HCT116 human colon cancer cell lines (27) were kindly provided by Dr. Bert Vogelstein (Johns Hopkins University, Baltimore, MD, USA). These cells were regularly maintained in McCoy's 5A medium (Mediatech, VA, USA) supplemented with $10 \%$ fetal bovine serum, $100 \mathrm{U} / \mathrm{ml}$ Penicillin, 100 $\mathrm{ug} / \mathrm{ml}$ Streptomycin and $2 \mathrm{mM}$ L-Glutamine.

\section{Analysis for apoptosis}

Smac-proficient or Smac-deficient cells were left untreated or treated with TG $(75 \mathrm{nM})$ for approximately $24 \mathrm{~h}$ and then processed for apoptosis detection by counting floating and adherent cells that exhibited morphologic features of apoptosis using a phase contrast microscope as reported previously (28).

\section{Western blotting}

Western blot analyses were performed by standard procedures as described previously (28). DR5 was detected using a monoclonal anti-human DR5 antibody (Oncogene Science, San Diego, CA, USA). To detect caspases 3,8 and 9 activation, antihuman pro-caspase 3 (BD Bioscience, San Jose, CA, USA), anti-human pro-caspase 8 antibody and antihuman pro-caspase 9 antibody (Assay designs/Stressgene, Ann Arbor, MI, USA) were used. Detection of Bid cleavage was done by anti-Bid antibody purchased from R\&D, Minneapolis, MN, USA. Cytochrome $\mathrm{c}$ was detected using a monoclonal anti-cytochrome c antibody from BD Bioscience, San Jose, CA, USA. Smac detection was done using a monoclonal anti-Smac antibody (Upstate Cell Signaling Solutions, Lake Placid, NY, USA). $\beta$-actin was detected using a monoclonal antibody purchased from Sigma Chemicals (St. Louis, MO, USA).

\section{Prepration of cytosolic fractions}

Smac-proficient or -deficient cells were left untreated or treated with $75 \mathrm{nM}$ TG for approximately $24 \mathrm{~h}$. Cytosolic fractions were prepared as we have described (28) and Western blotting was performed.

\section{Caspase 3 enzymatic assay}

Caspase 3 enzymatic assay was performed using a modified version of a protocol of Sigma caspase 3 fluorometric assay kit. In brief, Smac-proficient or deficient cells were treated with $75 \mathrm{nM}$ TG for 24 hrs. Cells were harvested and lysed in caspase 3 assay buffer containing $50 \mathrm{mM}$ HEPES ( $\mathrm{pH} 7.4$ ), 5 $\mathrm{mM}$ CHAPs, $5 \mathrm{mM}$ dithiothreitol, and $10 \mathrm{mM}$ sodium pyrophosphate. The lysates were clarified by centrifugation and $\sim 50 \mu \mathrm{g}$ of cell lysate was mixed with $200 \mu \mathrm{l}$ caspase assay buffer $(20 \mathrm{mM}$ HEPES (pH 7.4), $5 \mathrm{mM}$ DTT, $2 \mathrm{mM}$ EDTA, 0.1\% CHAPs and $15 \mu \mathrm{M}$ caspase 3 fluorogenic substrate (Ac-DEVDAMC, BD Pharmingen, San Jose, CA, USA) at room temperature for $60 \mathrm{~min}$. The caspase-3 activity was determined by Synergy HT Microplate Reader (BIO- 
TEK Instruments, Winoosski, VA, USA) with excitation at $380 \mathrm{~nm}$ and emission at $460 \mathrm{~nm}$.

\section{Northern blotting}

RNA extraction and Northern blot analyses were performed by standard procedures as we have described previously (29). A human DR5 cDNA was used as probe to detect DR5 mRNA levels. Ethidium bromide staining of the gel was used to indicate RNA integrity (29).

\section{Results and Discussion}

We used Smac-proficient $\left(\mathrm{Smac}^{+++}\right)$and Smacdeficient $\left(\mathrm{Smac}^{-/}\right)$HCT116 human colon cancer cells (27) in our study. In Smac-deficient cells, Smac alleles have been subjected to targeted deletion and thus, they do not express Smac protein. We investigated TG-induced apoptosis in Smacproficient and -deficient cells and as shown in Fig. 1, TG effectively induces apoptosis in Smac-proficient cells. However, in Smac-deficient cells, TG-induced apoptosis is clearly diminished. These results thus, indicate that Smac appears to play an important role in TG-induced apoptosis. We have previously reported that TG engages both the intrinsic and extrinsic pathways of apoptosis (29). For example, TG induces cytochrome $\mathrm{c}$ release from mitochondria into cytosol and activates caspases 9 and 3 (29). Next, we investigated the effect of TG on intrinsic pathway of apoptosis in both Smac-proficient and deficient cells. Fig. 2 shows that TG-induced apoptosis is coupled with cytochrome c release from mitochondria into cytosol in Smac-proficient cells. However, in Smac-deficient cells, cytochrome c release into cytosol is clearly diminished (Fig. 2). In Smac-proficient cells, TG also promotes increased levels of cytosolic Smac and as expected, Smacdeficient cells do not exhibit Smac expression (Fig. 2). Next, we investigated the effect of TG on caspases 9 and 3 activation in both types of cells and as shown in Fig. 3, caspases 3 and 9 activations are clearly blunted in Smac-deficient cells when compared with Smac-proficient cells. We also performed caspase 3 enzymatic assay and the results were consistent with those obtained by Western blot analyses (Fig. 4).

Previously, we had reported that TG-induced apoptosis was associated with TG-mediated upregulation of death receptor 5 (DR5) and activation of proximal caspase 8 (29). We had further reported that TG induced Bid cleavage suggesting that TG appeared to engage both intrinsic and extrinsic pathways via Bid cleavage

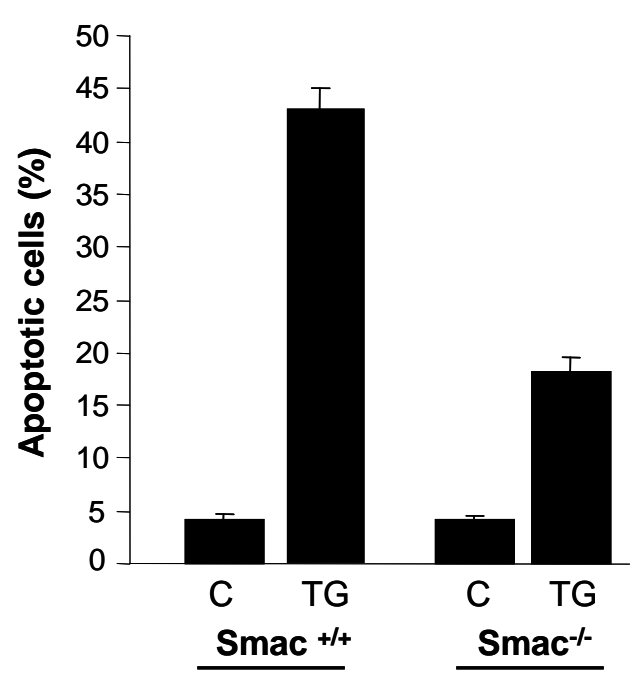

Figure 1. TG-induced apoptosis in Smac-proficient and Smacdeficient cells. Smac-proficient $\left(\mathrm{Smac}^{+/+}\right)$or Smac-deficient $\left(\mathrm{Smac}^{-1-}\right)$ HCT116 cells were left untreated or treated with TG $(75 \mathrm{nM})$ for approximately $24 \mathrm{~h}$ and then processed for apoptosis detection by counting floating and adherent cells using a phase contrast microscope as reported previously (28). The values represent mean »s.e.m. of three independent experiments.

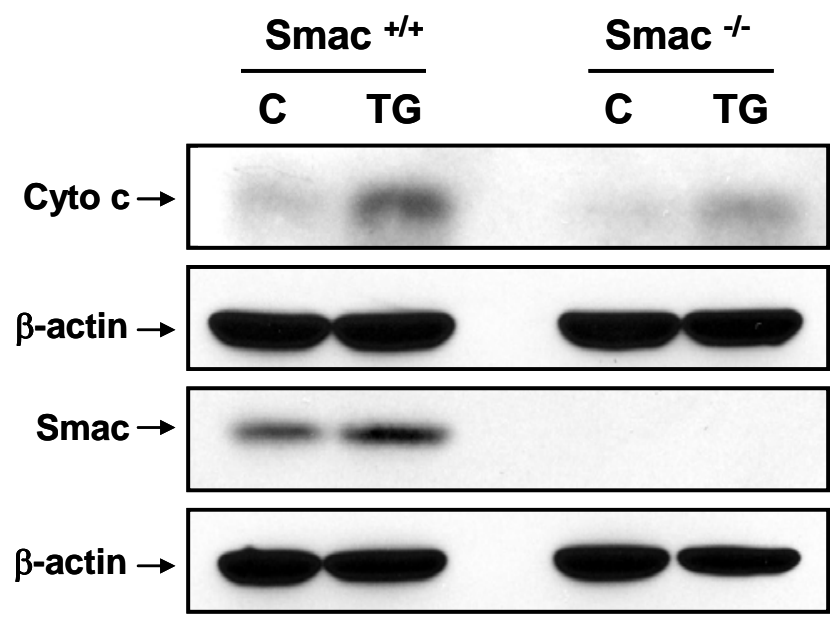

Figure 2. TG induced cytochrome $c$ release from mitochondria into cytosol in Smac-proficient and-deficient cells. Smacproficient $\left(\mathrm{Smac}^{+/+}\right)$or Smac-deficient $\left(\mathrm{Smac}^{-1-}\right)$ cells were left untreated or treated with $75 \mathrm{nM}$ TG for approximately $24 \mathrm{~h}$. Cytosolic fractions were prepared as we have previously described (28) and Western blotting was performed using the anti-cytochrome $c$ antibody or the anti-Smac antibody. The same blots were later probed with the anti- $\beta$-actin antibody to detect $\beta$-actin as a loading control.

(29). Next, we sought to investigate the effect of Smac deficiency on TG regulation of DR5 and caspase 8 activation as well as Bid cleavage. In this context, first, we investigated TG regulation of DR5 expression at the mRNA and protein levels in both 


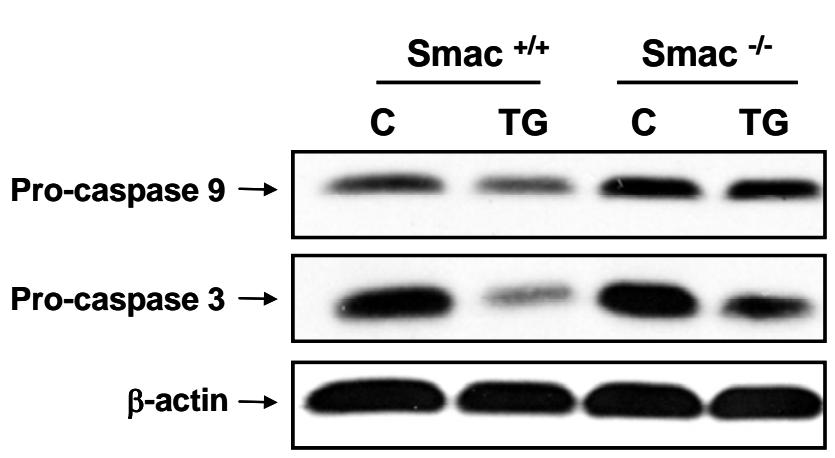

Figure 3. The effect of TG on caspases 3 and 9 in Smacproficient and -deficient cells. Smac -proficient $\left(\mathrm{Smac}^{+/+}\right)$or Smacdeficient $\left(\mathrm{Smac}^{-1}\right)$ cells were either left untreated or treated with TG $(75 \mathrm{nM})$ for approximately $24 \mathrm{~h}$. Cells were harvested and processed for Western blotting, the same blot was sequentially probed with the indicated antibodies including anti-caspases 3 and 9 , and $\beta$-actin.

Smac-proficient and -deficient cells and as shown in Fig. 5, TG upregulates DR5 expression in both Smac-proficient and-deficient cells and that is noted at both mRNA and protein levels. Next, we investigated TG effect on caspase 8 activation and Bid cleavage in both of these cell types. Interestingly, our results indicate that the constitutive levels of caspase 8 are lower in the Smac-deficient cells. In addition, TG-induced caspase 8 activation is diminished in the Smacdeficient cells when compared with that from Smacproficient cells (Fig. 6), although Bid cleavage appears to be comparable in both cell types.

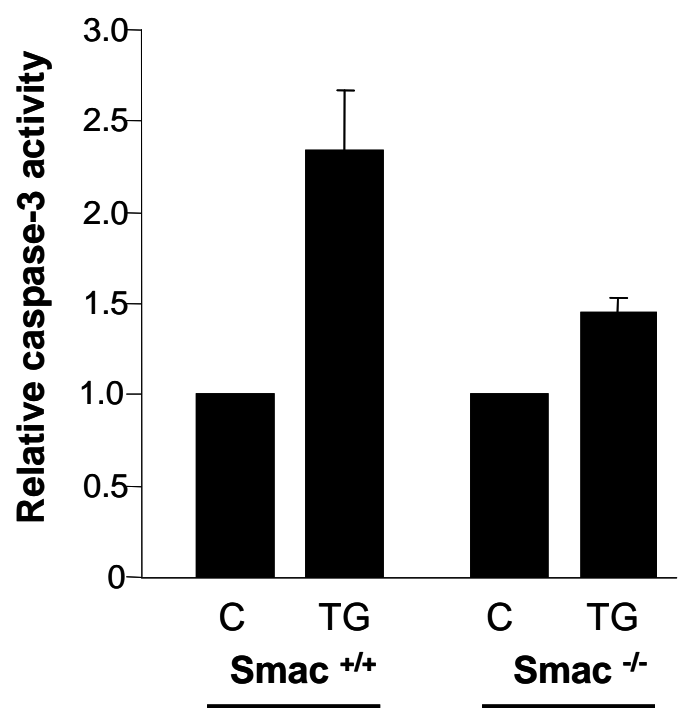

Figure 4. Quantitative results showing caspase 3 activation induced by TG in Smac-proficient and -deficient cells. Smac proficient $\left(\mathrm{Smac}^{+/+}\right)$or Smac-deficient $\left(\mathrm{Smac}^{-1}\right)$ cells were either left untreated or treated with TG $(75 \mathrm{nM})$ for approximately $24 \mathrm{~h}$. Cells were harvested and processed for caspase 3 enzymatic assay. The values represent mean $₫$ s.e.m. of three independent experiments.
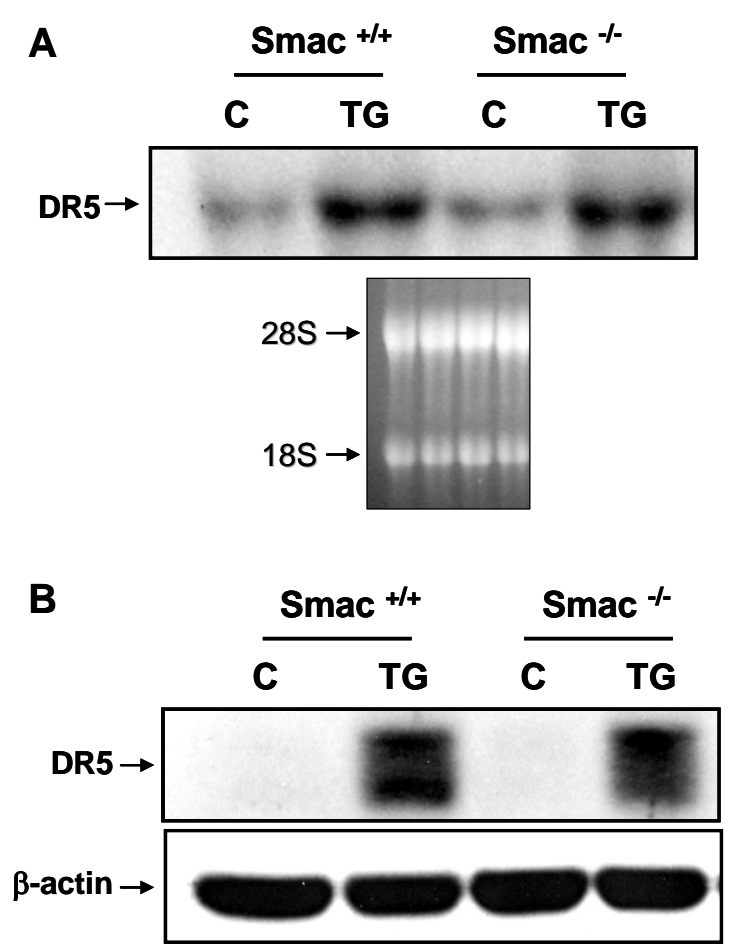

Figure 5. (A) A representative Northern blot shows that TG upregulates death receptor 5 (DR5) mRNA levels in Smacproficient and -deficient cells. Smac -proficient $\left(\mathrm{Smac}^{+/+}\right)$or Smacdeficient $\left(\mathrm{Smac}^{-1}\right)$ cells were either left untreated or treated with TG $(75 \mathrm{nM})$ for approximately $24 \mathrm{~h}$. Cells were harvested and total RNA was subjected to Northern analysis as we have previously described $(29,31)$. A cDNA fragment corresponding to human DR5 was used as a probe; ethidium bromide staining of the gel is shown to indicate RNA integrity. (B) A representative Western blot shows that TG upregulates death receptor 5 (DR5) protein levels in Smacproficient and -deficient cells. Smac -proficient $\left(\mathrm{Smac}^{+-}\right)$or Smacdeficient $\left(\mathrm{Smac}^{-1}\right)$ cells were either left untreated or treated with TG $(75 \mathrm{nM})$ for approximately $24 \mathrm{~h}$. Cells were harvested and processed for Western blot analysis using the anti-DR5 antibody. Same blot was subsequently probed with anti- $\beta$-actin antibody to determine comparable loading in each lane.

Here, we report that Smac appears to play an important role in TG-induced apoptosis. Smac is known to be a negative regulator of IAP. It is known that Smac mediates its pro-apoptotic function by interacting with IAP family proteins and alleviates the IAP-mediated inhibition of caspases 3, 7, and 9 (19-23). Our results show that TG-induced apoptosis is diminished in Smac-deficient cells and this is associated with reduction in cytochrome c release from mitochondria. These data thus indicate that adequate levels of Smac appear to be required for the release of cytochrome c from mitochondria and activation of intrinsic pathway, and imply that Smac appears to reside upstream of the intrinsic pathway. Interestingly, a recent study by Hasenjäger et al., (30) also suggests that Smac can induce cytochrome 


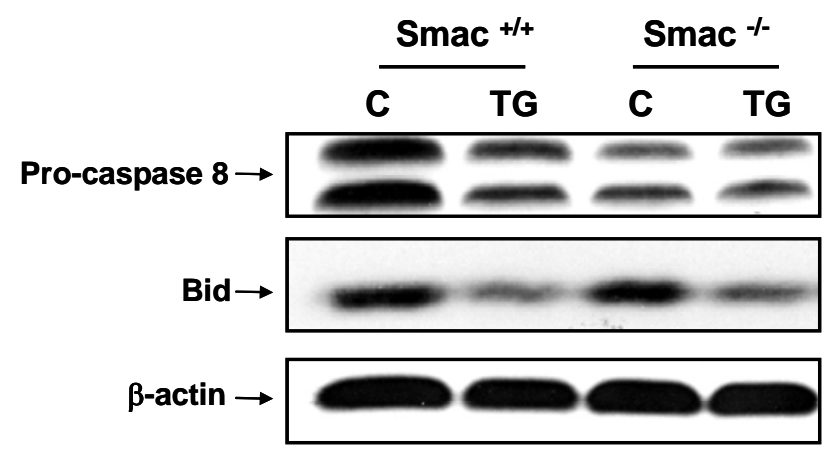

Figure 6. The effect of TG on caspase 8 activation and Bid cleavage in Smac-proficient and -deficient cells. Smac -proficient $\left(\mathrm{Smac}^{+++}\right)$or Smac-deficient $\left(\mathrm{Smac}^{-1-}\right)$ cells were either left untreated or treated with TG $(75 \mathrm{nM})$ for approximately $24 \mathrm{~h}$. Cells were harvested and processed for Western blotting using anti-caspase 8 or anti-Bid antibodies. Same blot was subsequently probed with anti$\beta$-actin antibody to detect $\beta$-actin, which serves as a loading control.

c release in a Bax/Bcl- $x_{L}$ independent manner. They used a virus-mediated Tet-off inducible Smac system to study the role of Smac in regulation of apoptosis and found that conditional expression of Smac induced apoptosis in HCT116 and DU145 human colon and prostate cancer cells (30). They further noted that Smac-mediated apoptosis was associated with cytochrome c release from mitochondria as well as alterations in the mitochondrial membrane potential. Thus, our data and the study from Hasenjäger et al., (30) suggest that Smac may be engaged in a positive feedback loop that leads to cytochrome c release from mitochondria.

Smac is an important molecule and in-depth studies are clearly needed to fully elucidate its regulation and function in response to various apoptotic insults. It is expected that the outcome of such studies will enhance our understanding of the signaling events that regulate cell death and survival under physiological and pathological conditions and will also facilitate the development of novel therapeutics to treat various pathological conditions in which cell death and survival signaling is deregulated. In this context, our results presented herein demonstrate the importance of Smac in ER-stress-induced apoptosis as well as in regulation of intrinsic pathway of apoptosis. Further Future studies are certainly needed to gain more insights into the molecular mechanisms involved in such regulation.

\section{Acknowledgments}

We thank Dr Bert Vogelstein for kindly providing the Smac-proficient and -deficient HCT116 cells. This work was supported in part by NIH Grants ES016668, ES005633 (to MSS) and CA121850 (to YH).

\section{References}

1. Furuya Y, Lundmo P, Short AD, Gill DL, Isaacs JT. The role of calcium, $\mathrm{pH}$, and cell proliferation in the programmed (apoptotic) death of androgen-independent prostatic cancer cells induced by thapsigargin. Cancer Res 1994;54:6167-75.

2. Krebs J. The role of calcium in apoptosis. BioMetals 1998;11:375-82.

3. Nutt LK, Chandra J, Pataer A, et al. Bax-mediated Ca2+ mobilization promotes cytochrome c release during apoptosis. J Biol Chem 2002;277:20301-8.

4. Kim BC, Kim HT, Mamura M, Ambudkar IS, Choi KS, Kim SJ. Tumor necrosis factor induces apoptosis in hepatoma cells by increasing $\mathrm{Ca}(2+)$ release from the endoplasmic reticulum and suppressing Bcl-2 expression. J Biol Chem 2002:277: 31381-9.

5. Tombal B, Denmeade SR, Gillis JM, Isaacs JT. A supramicromolar elevation of intracellular free calcium $([\mathrm{Ca}(2+)](\mathrm{i}))$ is consistently required to induce the execution phase of apoptosis. Cell Death Differ 2002;9:561-73.

6. Sagara Y, Inesi G. Inhibition of the sarcoplasmic reticulum $\mathrm{Ca} 2+$ transport ATPase by thapsigargin at subnanomolar concentrations. J Biol Chem 1991;266:13503-6.

7. Yang E, Korsmeyer SJ. Molecular thanatopsis: a discourse on the BCL2 family and cell death. Blood 1996;88:368-401.

8. Murphy AN, Bredesen E, Cortopassi G, Wang E, Fiskum G. Bcl-2 potentiates the maximal calcium uptake capacity of neural cell mitochondria. Proc Natl Acad Sci USA 1996;93:9893-8.

9. Shimizu S, Eguchi Y, Kamiike W, et al. Bcl-2 prevents apoptotic mitochondrial dysfunction by regulating proton flux. Proc Natl Acad Sci USA 1998;95:1455-9.

10. Foyouzi-Youssefi R, Arnaudeau S, Broner C, et al. Bcl2 decreases the free $\mathrm{Ca} 2+$ concentration within the endoplasmic reticulum. Proc Natl Acad Sci USA 2000;97:5723-8.

11. Nutt LK, Pataer A, Pahler J, et al. Bax and Bak promote apoptosis by modulating endoplasmic reticular and mitochondrial Ca2+ stores. J Biol Chem 2002;277, 9219-25.

12. Wolter KG, Hsu YT, Smith CL, Nechushtan A, Xi XG, Youle RJ. Movement of Bax from the cytosol to mitochondria during apoptosis. J Cell Biol 1997;139:12811292.

13. Hsu YT, Wolter KG, Youle RJ. Cytosol-to-membrane redistribution of Bax and $\mathrm{Bcl}-\mathrm{X}(\mathrm{L})$ during apoptosis. Proc Natl Acad Sci USA 1997;94:3668-72.

14. Nechushtan A, Smith CL, Hsu YT and Youle RJ. Conformation of the Bax C-terminus regulates subcellular location and cell death. EMBO J 1999;18:2330-41.

15. Boya P, Cohen I, Zamzami N, Vieira HLA, Kroemer G. Endoplasmic reticulum stress-induced cell death requires 
mitochondrial membrane permeabilization. Cell Death Differ 2002;9:465-7.

16. Shimizu S, Narita M, Tsujimoto Y. Bcl-2 family proteins regulate the release of apoptogenic cytochrome $\mathrm{c}$ by the mitochondrial channel VDAC. Nature 1999;399:483-87.

17. Du C, Fang M, Li Y, Wang X. Smac, a mitochondrial protein that promotes cytochrome c-dependent caspase activation by eliminating IAP inhibition. Cell 2000;102:33-42.

18. Verhagen AM, Ekert PG, Pakusch M, et al. Identification of DIABLO, a mammalian protein that promotes apoptosis by binding to and antagonizing IAP proteins. Cell 2000;102:43-53.

19. Chai J, Du C, Wu JW, Kyin S, Wang X, Shi Y. Structural and biochemical basis of apoptotic activation by Smac/DIABLO. Nature 2000;406:855-62.

20. Shiozaki EN, Shi Y. Caspases, IAPs and Smac/DIABLO: mechanisms from structural biology. Trends Biochem Sci 2004;29:486-94.

21. Wu G, Chai J, Suber TL, Wu JW, Du C, Wang X, Shi Y. Structural basis of IAP recognition by Smac/DIABLO. Nature 2000;408:1008-12.

22. Liu Z, Sun C, Olejniczak ET, et al. Structural basis for binding of Smac/DIABLO to the XIAP BIR3 domain. Nature 2000;408:1004-8.

23. Salvesen GS, Duckett CS. IAP proteins: blocking the road to death's door. Nat Rev Mol Cell Biol 2002;3:401-10. 24. Shiozaki EN, Chai J, Rigotti DJ, et al. Mechanism of XIAP-mediated inhibition of caspase-9. Mol Cell 2003;11:519-27.

25. Chai J, Shiozaki E, Srinivasula SM, et al. Structural basis of caspase-7 inhibition by XIAP. Cell 2001;104:769 80.

26. Sun H, Nikolovska-Coleska Z, Lu J, et al. Design, synthesis, and characterization of a potent, nonpeptide, cell-permeable, bivalent Smac mimetic that concurrently targets both the BIR2 and BIR3 domains in XIAP. J Am Chem Soc 2007;129:15279-94.

27. Kohli M, Yu J, Seaman C, et al. SMAC/Diablodependent apoptosis induced by nonsteroidal antiinflammatory drugs (NSAIDs) in colon cancer cells. Proc Natl Acad Sci U S A 2004;101:16897-902.

28. He Q, Luo X, Huang Y and Sheikh MS. Apo2L/TRAIL differentially modulates the apoptotic effects of sulindac and a COX-2 selective non-steroidal anti-inflammatory agent in Bax-deficient cells. Oncogene 2002;21:6032-40.

29. He Q, Lee DI, Rong R, et al. Endoplasmic reticulum calcium pool depletion-induced apoptosis is coupled with activation of the death receptor 5 pathway. Oncogene 2002;21:2623-33.

30. Hasenjäger A, Gillissen B, Müller A, et al. Smac induces cytochrome c release and apoptosis independently from $\mathrm{Bax} / \mathrm{Bcl}-\mathrm{x}(\mathrm{L})$ in a strictly caspase-3-dependent manner in human carcinoma cells. Oncogene 2004;23:4523-35.

31. Huang Y, He Q, Rong R, Hillman MJ, Sheikh MS. Sulindac sulfide-induced apoptosis involves death receptor
5 and the caspase 8-dependent pathway in human colon and prostate cancer cells. Cancer Res 2001;61:6918-24. 